Acta Poetica 28 (1-2)

PRIMAVERA-OTOÑO

2007

\title{
Walter Benjamin y el surrealismo: historia de un encantamiento revolucionario
}

\author{
Michael Löwy
}

El encuentro con el surrealismo en 1926-1927 despertó en Benjamin un “ardiente interés". El espíritu de un marxismo gótico que consistía en una magia del pasado, una iluminación desgarrante y el énfasis en la revuelta, representaba para Benjamin "la última instantánea de la inteligencia europea". En contra del "diletantismo moralizante" de los burgueses desencantados se postuló una politización revolucionaria que contaba con las fuerzas de la "ebriedad" y la carga de un pesimismo activo y organizado, idea lanzada por uno de los miembros activos del movimiento surrealista, Pierre Naville. El compromiso enérgico con la vía revolucionaria, que no es otra sino la vía marxista, encuentra su fuente en este pesimismo. Convergen en este punto el materialismo antropológico y la imagen dialéctica del sueño que Benjamin contrasta con el despertar concebido en el Libro de los pasajes como punto de oposición al movimiento surrealista.

The encounter with surrealism in 1926-27 roused a "passionate interest" in Benjamin. The spirit of gothic Marxism that consisted in a magic of the past, a rending illumination and the emphasis on revolt, represented in Benjamin "the last instant of the European intelligence". Against the "moralist dilettantism" of the disillusioned bourgeois, a revolutionary politics was demanded that counted on the forces of "inebriation" and the charge of an active and organized pessimism - an idea given by an active member of the surrealist movement, Pierre Naville. The energetic compromise with revolution which is no other than Marxist, had its source in that pessimism. It is a convergence point of anthropological materialism and the dialectic image of dream contrasted by Benjamin's concept of awakening, conceived in the Arcades' Project as an opposition to surrealism. 

Acta Poetica 28 (1-2)

PRIMAVERA-OTOÑO

2007

Michael Löwy

EHESS, Paris

\section{Walter Benjamin y el surrealismo: historia de un encantamiento revolucionario}

Fascinación es el término exacto que da cuenta de la intensidad de los sentimientos de Walter Benjamin en el momento de descubrir el surrealismo en 1926-27. Una fascinación que se traduce y comprende en sus esfuerzos por escapar al hechizo del movimiento fundado por André Breton y sus amigos.

Como es sabido, a partir de este descubrimiento nace el proyecto del Libro de los Pasajes parisinos. En una carta a Adorno de 1935, Benjamin describe en los términos siguientes la génesis de este Passagenwerk, al que se dedicará durante los trece últimos años de su vida: "Todo comenzó con El campesino de París de Aragon, del que por la noche en la cama no podía leer más de dos o tres páginas seguidas porque mi corazón latía tan deprisa que me obligaba a interrumpir la lectura". ${ }^{1}$

Benjamin vivió un tiempo en París en el verano de 1926 y de nuevo, en 1927, también en verano, después de su viaje a Moscú. Probablemente fue en ese momento cuando conoció

1 Walter Benjamin, Correspondance, trad. Guy Petitdemange, Paris, AubirMontaigne, 1979, II, pp. 163-164. Benjamin publicará en 1929 en la revista Literarische Welt la traducción de algunos pasajes de la obra de Aragon. 
el libro de Aragon (publicado en 1926) y otros escritos surrealistas. ¿Por qué esta atracción inmediata y esta convulsión interior? El perspicaz testimonio de Gershom Scholem, que le había visitado en París en 1927, aclara las motivaciones de lo que él llama el "ardiente interés" de Walter Benjamin por los surrealistas: había reconocido en estos "un cierto número de cosas que habían irrumpido en él mismo en el curso de los años precedentes". En otras palabras: "Benjamin leía las revistas en que Aragon y Breton proclamaban ideas que, en cierto sentido, salían al encuentro de su propia y más profunda experiencia". ${ }^{2}$ Veremos más adelante cuáles son estas "ideas".

No sabemos si Benjamin conoció a Breton o a otros surrealistas en esa ocasión, nada lo indica en su correspondencia. En cambio, parece, según Adorno y Scholem (en su prefacio a las Briefe) que hubiera intercambiado una correspondencia - hoy perdida o inencontrable — con el autor del Manifiesto del Surrealismo. $^{3}$

La huella de este descubrimiento puede percibirse — hasta cierto punto— en Dirección Única ([1928], 1978), que Benjamin publica en aquel momento (1928) de tal forma que Bloch creyó poder hablar de este libro como de una obra "típica" del "pensamiento surrealista" —afirmación bastante exagerada, y bien analizada, inexacta. ${ }^{4}$

De hecho, Benjamin intenta desvincularse de una fascinación que le parece peligrosa y quiere destacar la differentia specifica de su propio proyecto. En una carta dirigida a Scholem en noviembre de 1928 escribe que siente la necesidad de "arrancar este trabajo de una proximidad demasiado ostensi-

\footnotetext{
${ }^{2}$ Gershom Scholem, Walter Benjamin, histoire d'une amitié, Paris, CalmannLévy, 1981, pp. 157-158.

${ }^{3}$ Prefacio a Walter Benjamin, Correspondance, I, p. 9.

${ }^{4}$ Ernst Bloch, Héritage de ce temps, trad. Jean Lacoste, Paris, Payot, 1978, p. 340. Véase relacionada con este tema la crítica pertinente de Michel Izard, "Walter Benjamin et le surréalisme", Docsur, 12, junio 1990, p. 3.
} 
ble con el movimiento surrealista que, por muy comprensible y fundado que sea, podría convertirse para mí en algo fatal" - aunque no renuncie por ello a recoger la herencia filosófica del surrealismo.

¿En qué consiste esta "proximidad" "comprensible" e incluso "fundada"? Una obra reciente de Margaret Cohen, Profane Illumination, sugiere una interesante hipótesis. La autora se refiere a la práctica común a Benjamin y a Breton, que sitúa bajo el signo de un "marxismo gótico", alejándola de la versión dominante, de tendencia materialista metafísica y contaminada por la ideología evolucionista del progreso. No obstante, creo que esta autora sigue una pista falsa al definir el marxismo común a Benjamin y a los surrealistas como "una genealogía marxista fascinada por los aspectos irracionales del proceso social, una genealogía que intenta estudiar cómo lo irracional penetra la sociedad existente, soñando con utilizarla para efectuar el cambio social". 5 El concepto de "irracional" no aparece ni en los escritos de Benjamin ni en los de Breton. Este término remite a una visión racionalista del mundo heredada de la filosofía del siglo de las Luces, visión que, precisamente, ambos autores pretenden superar (en el sentido de la Aufhebung hegeliana). En contrapartida, el término de marxismo gótico es esclarecedor, siempre que este adjetivo se entienda en su acepción romántica, es decir, la fascinación por el encantamiento y lo maravilloso así como por los aspectos "embrujados" de las sociedades y de las culturas pre-modernas. La novela negra inglesa del siglo XVIII y algunas novelas románticas alemanas del siglo XIX son referencias "góticas" que encontramos en el mismo corazón de la obra de Breton y de Benjamin.

El marxismo gótico común a ambos sería, pues, un materialismo histórico sensible a la dimensión mágica de las culturas

\footnotetext{
${ }^{5}$ Margaret Cohen, Profane Illumination, Walter Benjamin and the Paris of Surrealist Revolution, Berkeley, University of California Press, 1993, pp. 1-2.
} 
del pasado, al momento "negro" de la revuelta, a la iluminación que desgarra, como un relámpago, el cielo de la acción revolucionaria. El término "gótico" también debe tomarse en el sentido literal como referencia positiva a ciertos momentos-clave de la cultura profana medieval; no es por casualidad que tanto Breton como Benjamin admiren el amor cortés de la Edad Media provenzal, que a los ojos del segundo constituye una de las más puras manifestaciones de iluminación. Y digo bien "profano" porque nada es tan abominable para los surrealistas como la religión en general, y la católica apostólica romana en particular. Benjamin no se equivoca al insistir en "la amarga y apasionada revuelta contra el catolicismo por la que Rimbaud, Lautréamont, Apollinaire engendraron el surrealismo". 6

Para comprender mejor en qué consiste la afinidad profunda de Benjamin con la obra de Breton, Aragon y sus amigos, debemos, no obstante, examinar más de cerca el artículo "El surrealismo. La última instantánea de la inteligencia europea" que Benjamin publicará en febrero de 1929 en la revista Literarische Welt. Redactado durante el año 1928, este texto difícil, a veces injusto, a menudo enigmático, siempre inspirado, lleno de imágenes y de alegorías extrañas, es de una extraordinaria riqueza. No se trata de un artículo de "crítica literaria" en el sentido habitual del término, sino de un ensayo poético, filosófico y político de una gran importancia, recorrido por intuiciones fulgurantes e "iluminaciones profanas" sorprendentes. Intentaremos reconstruir, sin la pretensión de ser exhaustivos, algunos de sus momentos esenciales.

\footnotetext{
${ }^{6}$ Walter Benjamin, "Le surréalisme. Le dernier instantané de l'intelligence européenne", en Mythe et Violence (M.V.). Paris, Maurice Nadeau, 1970, pp. 299, 301. $C f$. "Der Surrealismus. Die letzte Momentaufnahme der europäischen Intelligentz", en Gesammelte Schriften (G.S.), Frankfurt, Suhrkamp Verlag, 1977, vol. II, 1, pp. 297, 299. Un representante típico del marxismo "gótico" es sin duda Ernst Bloch, quien no oculta, sobre todo en sus primeras obras (L'Esprit de l'Utopie 1918-23), su admiración por la magia medieval y las catedrales góticas.
} 
A los ojos de Benjamin el surrealismo es todo menos una camarilla literaria —opinión que él atribuye a los "expertos" filisteos a los que irónicamente denomina "los nueve veces sabios". No se trata pues de un "movimiento artístico" sino de un intento de "hacer estallar desde dentro el campo de la literatura", gracias a un conjunto de experiencias (Erfahrungen) mágicas de alcance revolucionario; más exactamente, de un movimiento "iluminado", profundamente libertario y, a la vez, en busca de una posible convergencia con el comunismo.

Si esta práctica suscita en él un "candente interés", según Scholem, ¿no es acaso porque encuentra una gran similitud con la práctica que él había mantenido a lo largo de los diez años precedentes? Movido por una sensibilidad anarquista $-\mathrm{O}$ "nihilista revolucionaria", para emplear uno de sus términos favoritos- muy próxima a Sorel (ver su artículo "Crítica de la violencia" de 1921), Benjamin descubre el comunismo gracias a los hermosos ojos de Asja Lacis (Capri, 1923) y la filosofía marxista por la lectura de Historia y conocimiento de clase de Lukacs. Si, después de múltiples dudas, Benjamin decide no afiliarse al movimiento comunista, no deja por ello de ser una especie de simpatizante bastante sui generis, que se aleja del modelo habitual por la lucidez y el distanciamiento crítico - como atestigua claramente su Journal de Moscou de 192627. Una crítica que se nutre sin duda de la refrescante fuente libertaria que sigue recorriendo (a veces de manera subterránea) el seno de su obra.

Este íntimo parentesco político-cultural con el surrealismo es, además, mencionado explícitamente en los primeros párrafos del artículo, en el que Benjamin se describe a sí mismo como "el observador alemán”, situado en una posición "infinitamente peligrosa entre la fronda anarquista y la disciplina revolucionaria". Nada traduce de manera más concreta y activa la convergencia tan ardientemente deseada entre estos dos polos como la manifestación organizada por comunistas y liber- 
tarios en defensa de los anarquistas Sacco y Vanzetti. Ésta no pasó inadvertida para los surrealistas y Benjamin no deja de señalar el "excelente pasaje" (ausgezeichnete Stelle) de Nadja en el que se habla de los "apasionantes días de revuelta" que conoció París bajo el signo de Sacco y Vanzetti: "Breton asegura que, durante esos días, el boulevard Bonne-Nouvelle vio cómo se cumplía la estratégica promesa de revuelta que desde siempre se hallaba implícita en su nombre".7

Es cierto que Benjamin posee una idea extremadamente laxa del anarquismo. A la hora de describir el lejano/próximo origen del surrealismo, escribe: "Entre 1865 y 1875, algunos grandes anarquistas, sin ninguna relación entre ellos, trabajaron en sus máquinas infernales. Y lo sorprendente es que, sin saberlo, cronometraran sus mecanismos de relojería justo a la misma hora: cuarenta años después, y simultáneamente, estallaba la obra de Dostoïevski, de Rimbaud y de Lautréamont". ${ }^{8}$ Es evidente que la fecha, cuarenta años después de 1875, hace referencia al nacimiento del surrealismo con la publicación en 1924 del primer Manifiesto. El hecho de que Benjamin mencione a estos tres autores como "grandes anarquistas" no es sólo porque la obra de Lautréamont, "indudable bloque errático", pertenezca a la tradición insurreccional, o porque Rimbaud estuviera en la Comuna de París. Es sobre todo porque sus obras hacen saltar por los aires, como la dinamita de Ravachol, o, en otro plano, de los nihilistas rusos, el orden moral burgués, el "dilettantismo moralizante" de los Spießer y de los filisteos. ${ }^{9}$

\footnotetext{
${ }^{7}$ Walter Benjamin, "Le surréalisme”, pp. 297-298, 300. La traducción francesa del último pasaje es bastante defectuosa. $C f$. "Der Surrealismus", p. 305.

${ }^{8}$ Ibid., p. 308. No es necesario aclarar que esta genealogía no se corresponde en nada con la hecha por el mismo surrealismo, que no reconoce a Dostoyesvki como uno de sus precursores.

${ }^{9}$ El término "pequeño-burgués" de la traducción francesa no refleja toda la carga

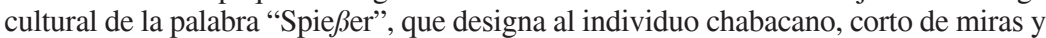
prosaico de la sociedad burguesa. $C f$. Walter Benjamin, "Der Surrealismus", p. 305.
} 
Pero la dimensión libertaria del surrealismo se manifiesta también de una manera más directa: "Desde Bakunin, a Europa le faltaba una idea radical de la libertad. Los surrealistas tienen esta idea". Es difícil encontrar, rebuscando entre toda la literatura que sobre el surrealismo se ha escrito en los últimos setenta años, una fórmula tan imponente, con la capacidad de expresar mediante palabras sencillas y contundentes, el "inquebrantable núcleo de noche" del movimiento fundado por André Breton. Según Benjamin, es la "hostilidad de la burguesía ante cualquier declaración de libertad espiritual radical" la que empujó al surrealismo hacia la izquierda, hacia la revolución y, a partir de la guerra del Rif, hacia el comunismo. Como es sabido, en 1927 Breton y otros surrealistas se afiliarán al Partido Comunista Francés. ${ }^{10}$

Esta tendencia a una politización y a un compromiso creciente no significan, a los ojos de Benjamin, que el surrealismo deba abdicar de su carga mágica y libertaria. Al contrario, son precisamente estas cualidades las que le permiten representar un papel único e irremplazable en el movimiento revolucionario: "Dar a la revolución las fuerzas de la ebriedad; esto es lo que pretende el surrealismo a través de sus escritos y sus acciones. Podemos decir que ésta es su tarea fundamental". Para llevar a cabo esta tarea es del todo necesario que el surrealismo supere una postura demasiado unilateral y acepte asociarse con el comunismo: "Todos sabemos que basta con un componente de viva ebriedad en cualquier tipo de acción revolucionaria, que se confunde con el componente anarquista; insistir en ella de una manera exclusiva supondría sacrificar por completo la preparación metódica y disciplinaria de la revolución a una praxis que oscila entre el trabajo y la celebración". ${ }^{11}$

${ }^{10}$ Walter Benjamin, "Le Surrealismus", pp. 306, 310.

11 Ibid., p. 311 . Benjamin también habla de "unir la revuelta a la revolución" (p. 310). 
¿En qué consiste esta "ebriedad", este Rausch del que Benjamin querría extraer las fuerzas para la revolución? En Dirección única (1928), Benjamin se refiere a la ebriedad como la expresión de la relación mágica entre el hombre antiguo y el cosmos, pero también deja entender que la experiencia ( $E r$ fahrung) del Rausch que caracterizaba esta relación ritual con el mundo ha desaparecido en la sociedad moderna. No obstante, en el ensayo de la Literarische Welt parece haberlo reencontrado, bajo una nueva forma, en el surrealismo. ${ }^{12}$

Se trata de una práctica que recorre numerosos escritos de Benjamin: la utopía revolucionaria debe pasar por el redescubrimiento de una experiencia antigua, arcaica, pre-histórica: el matriarcado (Bachofen), el comunismo primitivo, la comunidad sin clases ni Estado, la armonía original con la naturaleza, el paraíso perdido del que nos aleja la tempestad del "progreso", la "vida anterior" en la que la adorable primavera no había perdido todavía su olor (Baudelaire). En todos estos casos, Benjamin no propone una vuelta al pasado, sino más bien, según la dialéctica propia del romanticismo revolucionario, un desvío a través del pasado hacia un porvenir nuevo, que integre todas las conquistas de la modernidad desde $1789 .{ }^{13}$

Lo anteriormente expuesto vale también para la ebriedad moderna, de la que serían exponentes los surrealistas y que, en ningún caso, podría ser asimilada a la ebriedad arcaica de los tiempos primitivos. Además, Benjamin insiste en la distinción entre las formas inferiores y primitivas de la ebriedad - que incluirían el éxtasis religioso o el de las drogas - y una forma superior, llevada a cabo por el surrealismo en sus mejores momentos: la iluminación profana, “de inspiración materialis-

\footnotetext{
12 Ver con referencia a este tema las apreciaciones de Margaret Cohen, Profane Illumination, pp. 187-189.

13 A propósito de romanticismo revolucionario, ver de Robert Sayre y Michael Löwy, Révolte et mélancolie. Le romantisme à contre-courant de la modernité, Paris, Payot, 1992.
} 
ta y antropológica". Figura rica pero difícil de delimitar, esta forma no religiosa de la Erleuchtung se encuentra tanto en la forma de amor cortés como en la revuelta anarquista, en $\mathrm{Nad}$ ja y en el misterio presente en el corazón de lo cotidiano. La iluminación profana de los surrealistas, heredera del realismo filosófico de la Edad Media, a la que Breton recurrirá en su Introduction au discours sur le peu de réalité (1924), consiste, principalmente, en "las experiencias mágicas sobre las palabras", en las que "se interrelacionan consigna, fórmula de encantamiento (Zauberformel) y concepto". ${ }^{14}$

Si la civilización moderna capitalista/industrial, prosaica y de corto entendimiento - el mundo de los Spießer y de los filisteos burgueses - se caracteriza, como ha señalado acertadamente Max Weber, por el desencantamiento del mundo, la visión romántica del mundo, de la que el surrealismo es "la cola del cometa" (Breton), se apoya, sobre todo, en la aspiración ardiente - a veces desesperada - de un reencantamiento del mundo. Lo que distingue al surrealismo de los románticos del siglo XIX es, como bien lo comprendió Benjamin, el carácter profano, "materialista y antropológico" de sus "fórmulas de encantamiento", su naturaleza no-religiosa, e incluso profundamente antirreligiosa, sus "experiencias mágicas" y la vocación post-mística de sus "iluminaciones". 15

${ }^{14}$ Ibid., p. 305. Benjamin atribuye —de manera errónea en mi opinión- este tipo de experiencia mágica a "toda la literatura de vanguardia", incluido el futurismo. Y se queja — también creo que erróneamente- de una concepción insuficientemente profana en los surrealistas, que ejemplifica con el episodio de Madame Sacco, la vidente, evocada por Breton en Nadja. Irritado por esta "húmeda alcoba del espiritismo”, Benjamin se queja: “¿Quién no desearía ver a estos hijos adoptivos de la revolución romper de una manera más decisiva con todo aquello que se practica en los habitáculos de las damas de la caridad pasadas de moda, con los altos mandos en retirada, con los comerciantes emigrados?" (p. 300). En realidad, la imagen de la "vidente", como cualquiera de las figuras que aparecen en Nadja, es absolutamente profana y no tiene para Breton ningún significado "espiritista".

${ }^{15}$ Encontramos una excelente definición de iluminación profana -ilustrada por la mirada surrealista sobre París - en el libro de Richard Wolin sobre la estética de Benjamin: "Al igual que la iluminación religiosa, la iluminación profana captura 
Entre estas últimas, Benjamin dedica una especial atención al descubrimiento, hecho por los surrealistas, de las energías revolucionarias que se ocultan en "lo anticuado", en las "primeras construcciones de hierro, las primeras fábricas, las fotos antiguas, los objetos que empiezan a morirse, los pianos de cola". No obstante Benjamin no explica cuál es "la relación que une estos objetos a la revolución”. ¿Podría tratarse de un signo de la precariedad, de la historicidad, de la mortalidad de las estructuras, de los monumentos e instituciones burguesas? ¿Es un comentario irónico y subversivo a propósito de la pretensión burguesa por la "novedad" y la "modernidad"?16 A continuación, el párrafo parece avanzar en otra dirección ya que se plantea la miseria urbana e incluso la tristeza de los "barrios proletarios de las ciudades": "Antes de estos videntes y estos descifradores de signos nadie había comprendido cómo la miseria, no solamente la miseria moral sino también la miseria urbanística, la miseria de los interiores, los objetos humillados y humillantes, se transforman en nihilismo revolucionario". Incluso el mismo París, "el más soñado de estos objetos”, se convierte en fuente de experiencia revolucionaria, en la medida en que "sólo la revuelta hace resaltar de una manera ab-

los poderes de la ebriedad espiritual de modo que se produzca una revelación, una visión o una intuición que trascienda el estado prosaico de la realidad empírica; y ésta produce esta visión [...] sin recurrir a los dogmas del más-allá. Benjamin está pensando sin ninguna duda en el efecto de ebriedad, de trance, producido por las "novelas" surrealistas [...] en las que las calles de París [...] se transforman en un país de maravillas fantasmagóricas [...] en el que la monotonía de las convenciones queda resquebrajada por los poderes del azar objetivo. ¿Podría experimentarse la vida con la misma complacencia e indolencia, después de haber atravesado estos paisajes encantados?" (Richard Wolin, Walter Benjamin. An Aesthetic of Redemption, New York, Columbia University Press, 1982. p. 132).

${ }^{16}$ Véase a propósito de este tema la pertinente observación de Rainer Rochlitz: Para Benjamin "el surrealismo había demostrado cómo la imagen podía llevar a cabo una función revolucionaria, presentando el envejecimiento acelerado de las formas modernas como una producción incesante de lo arcaico que exige el verdadero sentido de la contemporaneidad. A través de las ruinas de la modernización, el surrealismo hizo ver la urgencia de un cambio revolucionario" (Le Désenchantement de l'art, Paris, Gallimard, 1992. p. 156). 
soluta el rostro surrealista" ${ }^{17} \mathrm{El}$ argumento de Benjamin oscila entre diferentes aproximaciones que, sin ser necesariamente contradictorias, están lejos de expresar un criterio unívoco. A no ser que ese criterio no sea el "mecanismo" consistente en "cambiar la mirada histórica sobre el pasado por la mirada política", es decir, encarar cada "objeto" desde el punto de vista de su futura — próxima— abolición revolucionaria. ${ }^{18}$

No obstante Benjamin reprocha al surrealismo, prisionero de ciertos "prejuicios románticos", la manera "demasiado rápida y para nada dialéctica de concebir la esencia de la ebriedad". Los surrealistas no se dan cuenta de que la lectura y el pensamiento también son fuente de iluminación profana: por ejemplo, "por muy apasionada que sea la búsqueda en relación con la ebriedad del hashish, no proporcionará ni la mitad de información que sobre ésta proporciona la iluminación profana del pensamiento. ${ }^{19}$ Esta crítica resulta especialmente extraña desde el momento en que los surrealistas — $i a l$ contrario que Benjamin! (ver su texto "Hachisch à Marseille")— no se han mostrado nunca demasiado inclinados a las experiencias de la droga, y han demostrado siempre un mayor interés por las Confesiones de un comedor de opio de Thomas de Quincey que por el consumo propiamente dicho de este dulce narcótico.

\footnotetext{
${ }^{17}$ Walter Benjamin, "Le surréalisme", p. 302.

18 Walter Benjamin, "Le surréalisme", p. 302. La traducción francesa es otra vez inexacta. Véase "Der Surrealismus", p. 300.

${ }^{19}$ Ibid., p. 311. Creo que Rainer Rochlitz se equivoca al interpretar este pasaje como un desahucio notificado del surrealismo por parte de Benjamin: "Si la lectura y el pensamiento también son formas de iluminación y de ebriedad [...] el irracionalismo surrealista ya no tiene justificación. Benjamin desea llevar la experiencia surrealista a un terreno que le es extraño: el terreno de la acción eficaz. Justificadamente, Georges Bataille ha rechazado esta fusión; la experiencia artística no puede ser instrumentalizada por la acción política" (Le Désenchantement de l'art, p. 154). El concepto de "irracionalismo", como ya hemos visto antes, no aparece en el ensayo de Benjamin, que por otra parte no pretende en absoluto renunciar a las "experiencias mágicas" del surrealismo. Además, la propuesta de Benjamin de dar a la revolución las fuerzas de la ebriedad está lejos de ser una simple "instrumentalización" del arte por la política.
} 
Entre las iluminaciones profanas en las que el texto de Benjamin es rico, no hay ninguna más sorprendente ni más extra$\tilde{n} a$ —en el sentido de la unheimlich alemana- por su fuerza premonitoria que el acuciante llamamiento a "la organización del pesimismo". Nada hay para Benjamin más irrisorio y estúpido que el optimismo de los partidos burgueses y de la socialdemocracia, cuyo programa político no es más que un "mal poema de primavera". Contra este "optimismo sin conciencia", este "optimismo de diletantes", inspirado por la ideología del progreso lineal, Benjamin descubre en el pesimismo el punto de convergencia efectivo entre surrealismo y comunismo. ${ }^{20}$ No hace falta decir que no se trata de un sentimiento contemplativo y fatalista, sino de un pesimismo activo, "organizado", práctico, completamente volcado en el objetivo de impedir, con todos los medios posibles, el advenimiento de lo peor.

¿En qué consiste el pesimismo de los surrealistas? Benjamin se refiere a ciertas "profecías" y al "presentimiento" de ciertas "atrocidades" en Apollinaire y Aragon: "Asaltan las editoriales, tiran al fuego las colecciones de poemas, matan a los poetas". Lo que impresiona en este pasaje no es solamente la previsión exacta de un acontecimiento que iba de hecho a producirse seis años más tarde —el auto de fe de libros "antialemanes" por los nazis en 1934; basta con añadir las palabras "de autores judíos" (o anti-fascistas) después de "colecciones de poemas" - pero también y sobre todo la expresión que utiliza Benjamin (y que no se encuentra ni en Apollinaire ni en Aragon) para designar esas "atrocidades": "un pogrom de poetas". ¿Se trata de poetas o de judíos? A no ser que ambos estén amenazados por este porvenir inquietante. Como veremos después, no es éste el único extraño "presentimiento" de este texto lleno de sorpresas.

En cambio, nos preguntamos a qué puede referirse el concepto de pesimismo aplicado a los comunistas; una doctrina

${ }^{20}$ Walter Benjamin, “Le surréalisme”, p. 312. 
que en 1928 celebra los triunfos de la construcción del socialismo en la uRss y la caída inminente del capitalismo, ¿no parece más bien un claro ejemplo de ilusión optimista? De hecho, Benjamin ha tomado el concepto de "organización del pesimismo" de una obra que califica de "excelente", La Révolution et les intellectuels (1926) de Pierre Naville. Miembro activo del grupo surrealista (había sido uno de los redactores de la revista La Révolution surréaliste), Naville había optado en aquel momento por el compromiso político en el movimiento comunista. Cuando intenta hacer compartir esta opción a sus amigos, les insta a abandonar "una actitud negativa de carácter anárquico" y aceptar "la acción disciplinada de la lucha de clases" y "comprometerse enérgicamente con la vía revolucionaria, la única vía revolucionaria: la vía marxista". Como ya hemos visto, Benjamin hace suya totalmente la práctica de Naville hacia los surrealistas, aun mostrándose más receptivo frente al momento libertario de la revolución.

Ahora bien, para Pierre Naville el pesimismo es la virtud más grande del surrealismo, en su realidad actual y más todavía en sus desarrollos futuros. Alimentado por las "razones que puede darse todo hombre consciente para no confiarse, sobre todo moralmente, a sus contemporáneos", el pesimismo que constituye "la fuente del método revolucionario de Marx" se presenta, ante sus ojos, como el único medio de "librarse de las nulidades y de las contrariedades de una época de compromiso". Rechazando el "burdo optimismo" de un Herbert Spencer - al que dedica el amable calificativo de "cerebro monstruosamente limitado" - o de un Anatole France, del que detesta "los halagos infames", Naville concluye: "es necesario organizar el pesimismo", "la organización del pesimismo" es la única consigna que nos impide debilitarnos. ${ }^{21}$

\footnotetext{
${ }^{21}$ Pierre Naville, La Révolution et les intellectuels, Paris, Gallimard, 1965, pp. 76-77, 110-117.
} 
No es necesario aclarar que esta apasionada apología del pesimismo era muy poco representativa de la cultura política del comunismo francés de aquella época. De hecho, Naville pronto sería excluido del Partido. La lógica de su anti-optimismo le llevará a las filas de la oposición comunista de izquierdas ("trotsquista"), de la que pronto será uno de los principales dirigentes. La referencia positiva a Naville, así como al mismo Trotsky - a propósito de la crítica del concepto de "arte proletario" - en el artículo de Benjamin, en un momento en el que el fundador de la Armada roja ya había sido expulsado del Partido comunista soviético y exiliado en Alma Ata, refleja su independencia de espíritu.

Según Walter Benjamin, el principal problema que plantea el libro de Naville es saber si la revolución exige primero el cambio de intenciones o el cambio de las circunstancias exteriores. Comprueba con satisfacción que "los surrealistas se han acercado cada vez más a la respuesta comunista”. ¿En qué consiste esta respuesta? "Pesimismo en general". Sí, sin duda, y total. "Desconfianza ante el destino de la literatura, desconfianza ante el destino de la libertad, desconfianza ante el destino del hombre europeo, pero sobre todo desconfianza ante toda acomodación: de clase, de los pueblos, de los individuos. Y tan sólo confianza ilimitada en la I. G. Farben y en el perfeccionamiento pacífico de la Luftwaffe".22

En este pasaje, ejemplo contundente de iluminación profana, Benjamin va mucho más allá que Naville — del que toma nada menos que el espíritu de desconfianza y el rechazo de los compromisos - y que los surrealistas. Su visión pesimista/revolucionaria le permite darse cuenta —intuitivamente pero con una sorprendente exactitud — de las catástrofes que aguar-

\footnotetext{
22 Walter Benjamin, "Le surréalisme". La frase con el problema fundamental se ha omitido en la traducción francesa. Véase "Der Surrealismus", p. 308: "Wo liegen die Voraussetzungen der Revolution? In der Änderung der Gesinnung oder der äus-seren Verhältnisse?".
} 
daban a Europa, perfectamente resumidas en la frase irónica sobre la "confianza ilimitada". Por supuesto que ni tan siquiera él, el más pesimista de todos, podía prever las destrucciones que la Luftwaffe acabaría infligiendo a las ciudades y poblaciones europeas; y ni tan siquiera podía imaginar que a la I.G. Farben se la conocería, apenas doce años más tarde, por la fabricación del gas Zyklon B utilizado para "racionalizar" el genocidio, ni que sus fábricas iban a utilizar a miles y miles de recluidos como mano de obra.

Sin embargo, Benjamin fue el único, entre todos los pensadores y dirigentes marxistas de aquellos años, que tuvo la premonición de los desastres monstruosos que la civilización industrial/burguesa en crisis podía engendrar. Aunque sólo sea por este párrafo — que no obstante es inseparable del restoeste ensayo de 1929 ocupa un lugar aparte dentro de la literatura crítica o revolucionaria de entreguerra.

La conclusión del artículo es una celebración - bastante incondicional — del surrealismo en tanto que heredero del "materialismo antropológico" de Hebbel, Georg Büchner, Nietzsche y Rimbaud. ¡Sorprendente lista de precursores! Este nuevo materialismo es distinto, según Benjamin, del materialismo de Vogt y de Bujarin —no podemos evitar pensar que Benjamin ha leído la crítica de Lukacs contra el materialismo de Bujarin, aparecida en 1926- al que califica de metafísico. ¿Qué significa exactamente "materialismo antropológico"? Benjamin no lo explica, pero sugiere que se trata de comprender que "la colectividad es un cuerpo vivo", cuando la tensión revolucionaria de ese cuerpo vivo colectivo se convierta en descarga revolucionaria, "sólo entonces la realidad se verá lo suficientemente desbordada como para responder a las exigencias del Manifiesto comunista".

¿Cuáles son esas exigencias? Benjamin no contesta, pero añade un comentario que puede considerarse el punto final del ensayo: "Hasta el momento los surrealistas son los únicos que 
han entendido la consigna que hoy ofrece [el Manifiesto comunista]. Uno después de otro cambian sus ademanes por la esfera de un sueño que marca los sesenta segundos de cada minuto". Esta afirmación es sorprendente por varios motivos. Por una parte parece, a pesar de las críticas a sus limitaciones, otorgar a los surrealistas el privilegio de ser los únicos capaces de situarse a la altura de las exigencias del marxismo - lo que situaría a un nivel inferior al resto de los intelectuales marxistas (¿Bujarin?). Por otra parte, lejos de identificar al movimiento surrealista con la Vague de rêves de Aragon - a quien cita al principio de este ensayo como el típico ejemplo del "estado heroico" del movimiento, cuando su "núcleo dialéctico" se encontraba todavía "encerrado" en una sustancia opaca-, Benjamin lo asocia directamente a la imagen dialéctica del sueño.

¿Qué significa esta enigmática alegoría de un despertador que marca "cada minuto durante sesenta segundos"? Benjamin sugiere sin ninguna duda que el valor único del surrealismo consiste en su disposición a considerar cada segundo como la puerta estrecha por la que puede entrar la revolución - parafraseando una fórmula que Benjamin no utilizará hasta mucho más tarde. Porque es de la revolución de lo que se está hablando, desde el principio hasta el final de este ensayo, y todas las iluminaciones profanas sólo adquieren su sentido en relación con este último y decisivo punto de fuga. ${ }^{23}$

\footnotetext{
23 Jacques Leenhardt señala unas apreciaciones muy interesantes sobre la relación entre despertar y sueño en Benjamin, pero creo que se equivoca al ver en la figura del despertador del ensayo sobre el surrealismo "la imagen de una cierta concepción del pensamiento racionalista" (Jacques Leenhardt, "Le passage comme forme d'expérience: Benjamin face à Aragon", en Heinz Wisman (ed.), Walter Benjamin et Paris, Paris, Cerf, 1986, p. 165). A Benjamin nunca se le hubiera ocurrido definir al surrealismo como una forma de pensamiento "racionalista" — concepto ausente en el artículo al igual que su contrario, "irracionalismo"-. Lo que caracteriza la práctica de los surrealistas y del mismo Benjamin en este ensayo es precisamente que éste no puede reducirse a la dicotomía "clásica" y establecida entre "racionalidad" e "irracionalidad".
} 
Un análisis del lugar que ocupa el surrealismo en Passagenwerk necesitaría otro artículo. Me limitaré aquí a llamar la atención sobre un aspecto directamente unido a esta conclusión del artículo de Literarische Welt. A menudo se señala la diferencia - incluso la contradicción- entre la práctica surrealista y la reflejada en el Libro de los pasajes como la oposición entre el sueño y el despertar. En efecto, desde los primeros borradores del proyecto se encuentra la siguiente afirmación:

Delimitación de la tendencia de este trabajo contra Aragon, mientras que Aragon persevera en el reino de los sueños, aquí se trata de encontrar la constelación del despertar (Erwachen). Mientras que en Aragon persiste un elemento impresionista: la "mitología" — siendo este impresionismo el responsable de numerosos filosofismos informes (gestaltlosen) del libro- aquí se trata de una disolución de la "mitología" en el espacio de la historia. Quedando claro que esto no puede darse más que por el despertar (Erweckung) de un conocimiento que todavía no sea consciente del pasado. ${ }^{24}$

Considerando que este texto fue redactado más o menos en la misma época que el artículo de 1929, ¿cómo hacerlo compatible con la imagen del despertar permanente como quintaesencia del surrealismo? A no ser que consideremos - lo que me parece la hipótesis más probable — esta delimitación referida exclusivamente a Aragon —y quizás a la "etapa heroica" del movimiento - y no al surrealismo tal y como éste se desarrolló durante los años 1927-28. Sobre todo teniendo en cuenta que ni la "mitología", ni el "impresionismo", ni los "filosofismos informes" forman parte de las —numerosascríticas que Benjamin dirige a Breton y a sus amigos en el ensayo de la Literarische Welt.

24 Walter Benjamin, Passagenwerk, Frankfurt, Suhrkamp Verlag, 1980, vol. I, pp. 571-572. 
Además, no podría reducirse la posición del Libro de los pasajes a una oposición estereotipada entre el sueño y el despertar. ¿No era la aspiración de Benjamin —al igual que la de Baudelaire y la de André Breton- la creación de un mundo nuevo en el que la acción fuera finalmente la hermana del sueño?

\section{BIBLIOGRAFÍA}

Benjamin, Walter, "Der Surrealismus. Die letzte Momentaufnahme der europäischen Intelligentz", en Gesammelte Schriften, Frankfurt, Suhrkamp, vol. II, 1, 1977.

- Correspondance, trad. Guy Petitdemange, Paris, Aubir-Montaigne, 1979.

- Passagenwerk, Frankfurt, Suhrkamp, vol V.I, 1980.

- "Le surréalisme. Le dernier instantané de l'intelligence européenne", en Mythe et Violence, Paris, Maurice Nadeau, 1970.

BLoch, Ernst, Héritage de ce temps, trad. Jean Lacoste, Paris, Payot, 1978.

Cohen, Margaret, Profane Illumination, Walter Benjamin and the Paris of Surrealist Revolution, Berkeley, University of California Press, 1993.

IZARD, Michel, "Walter Benjamin et le surréalisme", en Docsur, 12, junio 1990.

LEENHARDT, Jacques, "Le passage comme forme d'expérience: Benjamin face à Aragon", en Walter Benjamin et Paris, ed. Heinz Wisman, Paris, Cerf, 1986.

Naville, Pierre, La Révolution et les intellectuels, Paris, Gallimard, 1965.

Rochlitz, Rainer, Le Désenchantement de l'art, Paris, Gallimard, 1992.

SAYRE, Robert y Michael Löwy, Révolte et mélancolie. Le romantisme à contre-courant de la modernité, Paris, Payot, 1992.

SCHOLem, Gershom, Walter Benjamin, histoire d'une amitié, Paris, Calmann-Lévy, 1981.

Wolin, Richard, Walter Benjamin. An Aesthetic of Redemption, New York, Columbia University Press, 1982. 